\title{
Circadian preferences of birdwatchers in Poland: Do "owls" prefer watching night birds, and "larks" prefer daytime ones?
}

\author{
Martyna Fratczak ${ }^{1}$, Tim H Sparks $^{1}{ }$, Christoph Randler $^{2}$, Piotr Tryjanowski ${ }^{\text {Corresp. } 1}$ \\ 1 Poznan University of Life Sciences, Poznan, Poland \\ 2 Eberhard-Karls-Universität Tübingen, Tubingen, Germany \\ Corresponding Author: Piotr Tryjanowski \\ Email address: piotr.tryjanowski@gmail.com
}

Birdwatching is a very popular and increasing leisure activity, and the study and observation of birds is more popular in the morning due to the greater activity among birds at that time of day.

The aim of our study was to find out whether there was a relationship between the circadian preference of observers and their favourite bird species, and whether it was influenced by such factors as professional status, age and gender. In an e-mail survey we asked a total of 433 Polish ornithologists (professionals) or birdwatchers (non-professionals) for their morningness-eveningness preferences (four categories) and favourite (open choice) bird species, and received 143 responses. The temporal (circadian) preferences of respondents declined from early morning (35.7\%) to evening / nighttime (11.4\%). Circadian preference categories differed significantly by age, with early morning respondents significantly older. These preference categories did not differ significantly in terms of response time to the survey invitation or in the percentage of their favourite birds that were categorised as daytime birds. A total of 204 species were identified as favourite birds of which 34 species were mentioned by 5 or more respondents, with only two, the common crane Grus grus and the Eurasian pygmy owl Glaucidium passerinum mentioned by more than $10 \%$ of respondents. The white stork Ciconia ciconia was more popular with professionals than non-professionals and the swift Apus apus less popular. A significant gender $\times$ circadian preference interaction was detected for the percentage of favourite birds categorised as daytime birds, with fewer daytime birds among early morning female recorders. The presented results are obviously of a correlative nature, but open the door for further, more advanced study, and suggest there may be a need to investigate temporal biases when analysing citizen-based data. 
1 Circadian preferences of birdwatchers in Poland: Do "owls" prefer watching night birds,

2 and "larks" prefer daytime ones?

5 Martyna Fratczak ${ }^{1}$, Tim H. Sparks ${ }^{1,2}$, Christoph Randler ${ }^{3}$ \& Piotr Tryjanowski $^{1,4^{*}}$

7 1Poznań University of Life Sciences, Poznań, Poland

$8 \quad{ }^{2}$ Museum of Zoology, University of Cambridge, Cambridge, UK

$9 \quad{ }^{3}$ Eberhard Karls University of Tübingen, Tübingen, Germany

$10 \quad{ }^{4}$ Czech University of Life Sciences Prague, Prague, Czech Republic

*corresponding author: Piotr.Tryjanowski@gmail.com 
14

\section{Abstract}

Birdwatching is a very popular and increasing leisure activity, and the study and observation of birds is more popular in the morning due to the greater activity among birds at that time of day. The aim of our study was to find out whether there was a relationship between the circadian preference of observers and their favourite bird species, and whether it was influenced by such factors as professional status, age and gender. This has the potential to influence results, especially those based on citizen science observations. In an e-mail survey we asked a total of 433 Polish ornithologists (professionals) or birdwatchers (non-professionals) for their morningness-eveningness preferences (four categories) and favourite (open choice) bird species, and received 143 responses. The temporal (circadian) preferences of respondents declined from early morning (35.7\%) to evening / nighttime (11.4\%). Circadian preference categories differed significantly by age, with early morning respondents significantly older. These preference categories did not differ significantly in terms of response time to the survey invitation or in the percentage of their favourite birds that were categorised as daytime birds. A total of 204 species were identified as favourite birds of which 34 species were mentioned by 5 or more respondents, with only two, the common crane Grus grus and the Eurasian pygmy owl Glaucidium passerinum mentioned by more than $10 \%$ of respondents. The white stork Ciconia ciconia was more popular with professionals than non-professionals and the swift Apus apus less popular. A significant gender $\times$ circadian preference interaction was detected for the percentage of favourite birds categorised as daytime birds, with fewer daytime birds among early morning female recorders. The presented results are obviously of a correlative nature, but open the door for further, more advanced study, and suggest there may be a need to investigate temporal biases when analysing citizen-based data. 
38 Key words: environmental attitudes; birdwatching; circadian preference; morningness-

39 eveningness 


\section{Introduction}

Many factors influence human attitudes to animals, including animal traits such as colour, size, rarity and popularity, and human traits such as gender, age, education level and even food preferences (reviewed in: Prokop \& Randler, 2018). Obviously, both animal and human perception has co-evolved, and the latter changes due to life experience and education (Prokop, Kubiatko \& Fančovičová, 2008; Prokop \& Randler, 2018). Recently, dealings with animals have not necessarily been linked just to a targeted use (e.g. food source, guard role, beast of burden), but simply watching animals for fun, of which birdwatching is one example, is increasing worldwide (Kronenberg, 2016; Callaghan et al., 2018). Bird species differ in many ecological traits and these can also affect human behaviour, for example searching for information on particular species (Żmihorski, Dziarska-Pałac, Sparks, \& Tryjanowski, 2013; Correia, Jepson, Malhado, \& Ladle, 2016, 2017) and even willingness to pay for their conservation (Raab, Randler, \& Bogner, 2018). However, people watching birds, and other taxa, differ in many psychological and physical traits, and one very marked behavioural difference is their particular morningness-eveningness spectrum of activity (Werner, Geisler, \& Randler, 2015). In the case of bird observation, this can affect not only intellectual and physical peak performance during the day (Pica, Amato, Pierro, \& Kruglanski, 2015; Randler, Faß1, \& Kalb, 2017; Arrona-Palacios \& Díaz-Morales, 2018), but also punctuality (Werner et al., 2015) and risk-taking (Wang \& Chartrand, 2015), which can be useful in finding and watching rare birds, which is a particularly focussed activity of some birdwatchers (Żmihorski, Sparks, \& Tryjanowski, 2012; Callaghan et al., 2018). 
62 The morningness-eveningness preference may change in relation to age, gender, and even

63 seasons (Pica et al., 2015; Randler, Faß1, et al., 2017), which also makes this interesting to study

64 in terms of the potential relationship between humans and birds. Birds are a very variable

65 taxonomical group. There are more than 10,000 species, they live in different habitats, and they

66 have different seasonal and daily activities mainly related to breeding, wintering and seasonal

67 migrations (Del Hoyo, Elliott, \& Sargatal, 1992-2011; Jetz, Thomas, Joy, Hartmann, \& Mooers,

68 2012), all of which combine to strongly affect people who watch and study birds (Callaghan et

69 al., 2018). Because people have different financial resources, time availability, personal

70 preferences, skills, knowledge, and commitment, they may focus on different bird

71 species/taxonomic groups (Lee \& Scott, 2004; Prokop et al., 2008; Yarwood, Weston, \& Garnett,

72 2014). Furthermore, the psychological terminology on circadian preference and morningness-

73 eveningness has always been linked to bird behaviour, as shown by use of the classical phrase

74 “owls vs. larks” (Pica et al., 2015; Putilov, Donskaya, \& Verevkin, 2015). Furthermore,

75 differences in daily patterns of data collection, and a focus on particular bird species may attach

76 a bias to obtained results. Given the current debate on the importance of data quality (La \&

77 Somveille 2019) this is a very pertinent issue, also in the context of bird monitoring schemes

78 (Snäll et al., 2011).

However, we do not know of a single study that has linked morningness-eveningness to

81 preferences of particular bird species or groups and therefore it is difficult to specify exact testable hypotheses. However, we hazard a guess that people with stronger morningness than eveningness will prefer morning rather than nocturnally active bird species, and vice versa.

84 Therefore, based on an e-mail questionnaire to birdwatchers, we attempted to answer whether: 
85 (1) there is a relationship between observer morningness-eveningness and favourite bird species;

86 (2) there are differences between amateur birdwatchers and professional ornithologists in this

87 human trait; (3) potential differences are influenced by other factors (age and gender)?

88

89

90

91

92

\section{Methods}

\section{Data collection}

At 00:00 hours on the 19 February 2019 the first author (MF) sent an e-mail questionnaire to 433 (356 male, 77 female) Polish ornithologists and advanced birdwatchers and asked for a response by e-mail. Potential participants were chosen by preparing a database of e-mail addresses using information provided in scientific publications, including short notes published in Polish naturalists' journals dedicated to birds. We accessed 28 journals publishing even local records of rare species, unusual behaviour, species lists and even notes on untypical plumage (mainly in Polish. The whole list of accessed journals is available in Supplementary Material). Participants were asked for up to five favourite bird species (without any suggestion as to local or exotic), their year of birth, and their classical circadian general type as used in similar studies (Randler, Schredl, \& Göritz, 2017) as follows: (A) definitely morning type; (B) more morning than evening type; (C) more evening than morning type; and (D) definitely evening and night type. Measuring circadian preference in this way could be criticised because it is based on a single question, but Loureiro and Garcia-Marques (2015) showed that results were rather similar, whether based on only a single question or derived from the full scale. Randler, Schredl et al. (2017) showed that results were comparable, irrespective whether a four-item version or a singleitem measurement was used; both measures of chronotype revealed identical results. This is also in line with Loureiro and Garcia-Marques (2015). We closed the survey two weeks after the 
108 initial e-mail posting. For each respondent we recorded when their reply was sent and used this

109 to calculate the time to respond, expressed in decimal hours.

110

111 Statement on ethical approval

112 Research reported in this manuscript has been conducted in an ethical and responsible manner, in

113 full compliance with all relevant codes of experimentation and legislation.

\section{Data analyses}

116 For further analyses we added information on gender and we divided participants, according to

their academic degrees and jobs, into two general categories: professional and non-professional

118 (amateurs). The suggested favourite bird species were divided into two broad categories nighttime birds (such as owls, rails etc.) and daytime birds (the majority of passerines, cranes, ducks etc.) using data from handbooks (mainly Del Hoyo et al., 1992-2011). For each respondent the percentage of favourite birds that were daytime birds was calculated.

Because of the rather skew nature of some of the variables it was decided to focus on nonparametric tests. Kruskal Wallis tests, adjusted for ties, were used to compare scale variables to categories, and chi squared tests to compare categories with one another. Where expected numbers were so low as to question the validity of chi squared results, Fisher exact tests were used. For testing individual species such tests were restricted to species mentioned by 10 or more respondents. Spearman correlations were used to compare scale variables. Binary logistic regression was used to compare the proportions of favourite birds identified as daytime birds to 130 year of birth, professional status, gender and time preference category. The model initially 
131 included all main effects and two-way interactions, but nonsignificant two-way interactions were

132 dropped one-by-one until only the main effects and any significant interactions remained.

133

134 Year of birth was used in analyses, but is presented as age in results. The significance threshold 135 in all analyses was taken as $\mathrm{P}=0.05$. All analysis was carried out in Minitab 18 and SPSS 24.

\section{Results}

\section{Description of participants}

139 Complete or near complete responses were received from 143 individuals (33.0\%), with response times ranging from 3 minutes to 14 days (the cut-off point). Response rates were $31.7 \%$ for 141 males and $39.0 \%$ for females with no significant difference between the two $\left(\chi_{1}^{2}=0.73, \mathrm{P}=0.394\right)$.

Response times were positively skewed with a median of 10 hours and a mean of 44 hours. Years of birth were provided by 140 individuals, indicating a mean age of 45 years (range 2285). The professional status of the 142 birders providing detail was roughly evenly split between non-professionals (51.4\%) and professionals (48.6\%). As expected from the targeted individuals, the majority of respondents $(79 \%)$ were male. The circadian preferences of respondents changed from early morning; 50 (35.7\%) coded A, $41(29.3 \%)$ coded B, $33(23.6 \%)$ coded C and 16 $149(11.4 \%)$ coded D, 3 people didn't provide a response to this question.

It is worth noting that 11 complaints (mainly about the aims and methods of the study) were also received, which in combination with other responses indicate a response rate of $35.6 \%$ of the targeted population. Nine of the complaints came from professional birders and a chi squared test 
154 indeed confirmed that professionals were significantly more likely to complain $\left(\chi_{1}^{2}=4.70\right.$,

$155 \mathrm{P}=0.030)$. There was no significant association between gender and complaining $\left(\chi_{1}^{2}=1.18\right.$, $156 \mathrm{P}=0.277)$. Furthermore, those complaining were significantly older $(\mathrm{H}=11.91, \mathrm{P}=0.001$, medians 15764,42 years).

Professional birdwatchers were significantly older $(\mathrm{H}=5.89, \mathrm{P}=0.015)$ than non-professionals (median ages 47 and 41 years respectively), but did not differ significantly in response times to the survey $(\mathrm{H}=0.72, \mathrm{P}=0.395)$ or in the percentage of their favourite birds that were categorised as daytime birds $(\mathrm{H}=0.29, \mathrm{P}=0.589)$. There was no significant association between professional status and gender $\left(\chi_{1}^{2}=0.76, \mathrm{P}=0.384\right)$ or between professional status and circadian preference ( $\left.\chi_{3}^{2}=5.34, \mathrm{P}=0.149\right)$

Female respondents were significantly younger than male respondents $(H=11.91, P=0.001$, medians of 37 and 45 years respectively), but did not differ significantly in terms of response times $(\mathrm{H}=0.04, \mathrm{P}=0.835)$ or percentage of their favourite birds that were categorised as daytime birds $(\mathrm{H}=0.12, \mathrm{P}=0.726)$. There was a suggestion that females were less likely to be category $\mathrm{A}$ recorders but this did not quite reach significance (Fisher exact test $\mathrm{P}=0.053$ ).

Circadian preference categories differed significantly in age, with category A respondents noticeably older $(\mathrm{H}=10.56, \mathrm{P}=0.014$, medians $48,41,40$ and 42 years respectively for categories A-D). Circadian preference categories did not differ significantly in terms of response time $(\mathrm{H}=3.29, \mathrm{P}=0.349)$ or percentage of their favourite birds that were categorised as daytime birds $(\mathrm{H}=2.29, \mathrm{P}=0.514)$. 
Favourite bird species

179 180 181 182 183 184 185 186 187 188 189 190

$196=5.09, \mathrm{P}=0.024$ ) and one significant interaction (gender $\times$ circadian preference: $\chi_{3}^{2}=14.26$, 197 198

A total of 204 species were identified as favourite birds, of which $184(90.2 \%)$ were classified as daytime birds. A full table of species indicating their daytime/nighttime category is given in Supplementary Material 1 . The 34 species mentioned by 5 or more respondents are listed in Table 1. Only two species, the common crane Grus Grus and the Eurasian pygmy owl Glaucidium passerinum, were mentioned by more than $10 \%$ of respondents. Only the 12 species that were mentioned 10 or more times were subject to further analysis. This additional analysis suggested that the white stork Ciconia ciconia was more popular with professionals than nonprofessionals (13\% cf. 3\%) and the swift Apus apus less popular (3\% cf. 12\%). No significant gender preferences were detected in this subset of species. There was a significant difference in the circadian preference categories for swift which was not mentioned by any of the category A respondents.

There were no significant Spearman correlations between age, response times and percentage of favourite birds that were categorised as daytime birds (all $\mathrm{P}>0.297$ ).

Binary logistic regression on the proportion of favourite birds categorised as daytime produced an overall significant model $\left(\chi_{9}^{2}=23.47, \mathrm{P}=0.005\right)$ with one significant main effect (gender: $\chi_{1}^{2}$ $\mathrm{P}=0.003)$. In addition, circadian preference was very close to significance $\left(\chi_{3}^{2}=7.80, \mathrm{P}=0.0503\right)$. This interaction is shown in Figure 1 where female respondents in category A reported fewer 
199 favourite daytime birds than their male counterparts, and in contrast to the pattern in other 200 categories.

\section{Discussion}

203 204 205

The number of participants may appear lower than expected in western European countries such as the Netherlands, Germany and especially the UK (Cocker 2012). But in reality we asked a large proportion of bird observers that usually participate in national citizen science projects in Poland, such as Common Birds Monitoring Scheme, Winter Bird Counts and BirdFeeder Project. These schemes usually attract only 100-180 people. We used an e-mail based questionnaire, with an overall response rate of $35.6 \%$ which may appear low, but is similar to the average rate in other studies using similar methods in psychology (Cook, Heath, \& Thompson, 2002; Sheehan, 2001). We also noted with great interest the few complaining e-mails where respondents, mainly professionals, expressed concerns over the aims and methodology of the study. It may seem obvious that a significantly greater rate of complaint would derive from professional ornithologists rather than amateur birdwatchers, because professionals focus much more on science than simply gaining pleasure from watching birds (e.g. Yarwood et al., 2014; Yarwood, Weston, \& Symonds, 2019 and see also below).

The study also suggests that watching birds is still more popular among men than women, similar to other studies in Poland, but which were based on a much smaller sample size (Sklodowski \& Jurkowska, 2015). However, it is interesting to note that women participating in our study were significantly younger than men, which is a sign of an encouraging (probably global) trend that birdwatching has recently become more popular with women (Cooper \& 
222 Smith, 2010). The most represented circadian preference was the "early morning type", a finding

223 similar to that found by Raab et al. (2018). Moreover, those authors even suggested that students

224 with a morningness preference were more likely to be protective of, and appreciative towards,

225 nature, including birds. Furthermore, early morning (lark type) people more often participated in

226 voluntary activities, shared information, were open to new ideas, were faster and more punctual

227 (Song \& Stough, 2000; Werner et al., 2015). On the other hand, if we compare birders with the

228 general Polish population (e.g. Jankowski, 2013; Tęgowska, Sobocińska, \& Maliszewska, 2014)

229 there is still apparent a visible bias to the early morning type. In a correlative-type study like ours

230 it is impossible to determine if early morning types are more likely to take up an ornithological

231 career, or indeed if they just have to get up early to watch more bird species. This can only be

232 resolved if a representative sample of Polish people was surveyed and matched for gender and 233 age, because there are significant age effects in circadian preference in the adult population (e.g.

234 Randler et al., 2016).

235

236

237

238

239

240

241

242

243

244

The 143 respondents mentioned 204 species as favourite birds with great variation between respondents, but some patterns are worth noting. Only two species, the common crane and the Eurasian pygmy owl, were mentioned by more than $10 \%$ of respondents. We did not ask why people decided on their particular species, but Eurasian pygmy owl was a surprise to us. The common crane is a more obvious choice because it is a big charismatic bird with a characteristic call, an increasing population size and is also represented in Polish culture and art (e.g. Wąs, 2013). Interestingly, the white stork was a more popular choice with professionals than with nonprofessionals but the swift showed an opposite pattern. The white stork is a Polish icon, well recognised, easy-to-spot even by beginners, and very popular in both scientific studies and the 
245 cultural life of Poland (Kronenberg, Andersson, \& Tryjanowski, 2017). There are long term-data

246 on white storks that permit advanced statistical analyses and so it is often chosen as a study

247 species by ornithologists, although it is not very attractive to classical birdwatchers because it is

248 still common, but is more exciting to visitors to Poland rather than local birdwatchers

249 (Kronenberg, 2016; Kronenberg et al., 2017). In choosing study species, ornithologists follow

250 different criteria, based on the probability of obtaining a good sample size, conservation status,

251 and even size and behaviour (Yarwood et al., 2014, 2019). After some years of study, they know

252 much about the biology of the species, including its secrets, and are fascinated by the species

253 which then also becomes a favourite bird (personal experience of the authors). It is likely that

254

255

256

257

258

259

260

261

262

263

264

265

266

267

preferences change over time and are sensitive to mass-media information making species more or less charismatic in recent years (Żmihorski et al., 2012; Correia et al., 2016, 2017). In our sample, swift is perhaps an indicator of changes in recent times, because the species is an object of recent debate focused on bird conservation in urban areas and information has been promoted on this species biology, ecology and importance to humans (Luniak \& Grzeniewski, 2011). It is interesting that this species was not suggested as a favourite bird by any of the "early morning" respondents, which fits especially well with the late afternoon and early evening activity of swifts.

A number of other interesting patterns appear evident in Table 1 but failed to achieve either significance or sufficient sample size for testing. A study based on a larger sample would be needed to confirm or refute any of these apparent patterns. Probably a more advanced study should compare species choice with other factors, for example how much attention she/he pays to that particular bird species, how many publications are dedicated to that particular species, and 
even a measure of emotional attachment. Similar studies could be useful for understanding the choice of different outdoor activities between people, as well as a deeper understanding of the variability of other groups of passionate recreationalists (e.g. anglers, hunters, mountain climbers, cf. Wałega et al., 2017). Given that much of the data used to estimate species population sizes and geographical distributions, and to produce bird guides, originate from recorders of which our respondents were a sample, it is important to know if their behaviour may subconsciously influence their records. Furthermore, a better understanding of the reasons for the popularity of species could help enormously in planning for, and funding, their conservation. One important aspect that chronobiology may contribute to bird research is the influence on citizen science programs. Citizen science programs, such as eBird rely heavily on the submissions of many volunteer birdwatchers (Wiersma 2010). However, the reporting of given species may be significantly influenced if the chronotype of the birdwatchers and the circadian rhythms of specific species do not map. Early morning bird species may go underreported most birdwatchers are not morning oriented themselves. In a similar manner, a higher proportion of "owls" in birdwatchers may lead to a better registration of owls in these databases. Of course, these assumptions need further study based on larger samples.

Conclusion

Although much is known about birds and the importance of citizen science, only scarce evidence is available about the nature of birdwatchers, both professional and amateur. These data, especially about their morning or evening preference, may severely influence data collection behaviour but, in this study, we were able to show that there is only a weak influence of 
290 circadian preference on leisure birdwatching, and thus, we assume a minimal or even absent 291 influence of circadian preference on birdwatching.

\section{References}

295

Arrona-Palacios, A., \& Díaz-Morales, J. F. (2018). Morningness-eveningness is not associated with academic performance in the afternoon school shift: Preliminary findings. British Journal of Educational Psychology, 88(3), 480-498.

299

Callaghan, C. T., Slater, M., Major, R. E., Morrison, M., Martin, J. M., \& Kingsford, R. T. 301 (2018). Travelling birds generate eco-travellers: The economic potential of vagrant birdwatching. Human Dimensions of Wildlife, 23(1), 71-82.

Cocker, M. (2012). Birders. Random House, London.

Cook, C., Heath, F., \& Thompson, R. L. (2000). A meta-analysis of response rates in web-or 307 internet-based surveys. Educational and Psychological Measurement, 60(6), 821-836.

Cooper, C., \& Smith, J. (2010). Gender patterns in bird-related recreation in the USA and UK. 
312 Correia, R. A., Jepson, P. R., Malhado, A. C., \& Ladle, R. J. (2016). Familiarity breeds content:

313 assessing bird species popularity with culturomics. PeerJ, 4, e1728.

314

315 Correia, R. A., Jepson, P., Malhado, A. C., \& Ladle, R. J. (2017). Internet scientific name 316 frequency as an indicator of cultural salience of biodiversity. Ecological indicators, 78, 549-555.

Del Hoyo, J., Elliott, A., \& Sargatal, J. (1992-2011). Handbook of the Birds of the World. Vol. IXII. Barcelona: Lynx edicions.

Jankowski, K. S. (2013). Polish version of the reduced Morningness-Eveningness Questionnaire.

Biological Rhythm Research, 44(3), 427-433.

Jetz, W., Thomas, G. H., Joy, J. B., Hartmann, K., \& Mooers, A. O. (2012). The global diversity of birds in space and time. Nature, 491(7424), 444.

Kronenberg, J. (2016). Birdwatchers' wonderland? Prospects for the development of birdwatching tourism in Poland. Journal of Ecotourism, 15(1), 78-94.

Kronenberg, J., Andersson, E., \& Tryjanowski, P. (2017). Connecting the social and the ecological in the focal species concept: case study of White Stork. Nature Conservation, 22, 79. of bird occurrence. Ecography, in press. 
336 Lee, J. H., \& Scott, D. (2004). Measuring birding specialization: A confirmatory factor analysis.

337 Leisure Sciences, 26(3), 245-260.

338

339

Loureiro, F., \& Garcia-Marques, T. (2015). Morning or Evening person? Which type are you?

340

Self-assessment of chronotype. Personality and Individual Differences, 86, 168-171.

341

342 experience from Poland. Ecologia Urbana, 23, 3-5.

344 locomotors' preference for morningness. Personality and Individual Differences, 76, 158-160. attitudes toward, birds. Anthrozoös, 21(3), 221-235. attitudes toward animals. Ethnozoology (pp. 447-466). Academic Press.

Putilov, A. A., Donskaya, O. G., \& Verevkin, E. G. (2015). How many diurnal types are there? A search for two further "bird species". Personality and Individual Differences, 72, 12-17. 
357 Raab, P., Randler, C., \& Bogner, F. (2018). How Young "Early Birds" Prefer Preservation,

Randler, C., Faß1, C., \& Kalb, N. (2017). From Lark to Owl: developmental changes in morningness-eveningness from new-borns to early adulthood. Scientific Reports, 7, 45874.

Randler, C., Freyth-Weber, K., Rahafar, A., Jurado, A. F., \& Kriegs, J. O. (2016). Morningnesseveningness in a large sample of German adolescents and adults. Heliyon, 2, e00200.

Randler, C., Schredl, M., \& Göritz, A. S. (2017). Chronotype, sleep behavior, and the big five personality factors. Sage Open, 7(3), 2158244017728321.

Sheehan, K. B. (2001). E-mail survey response rates: A review. Journal of Computer-mediated Communication, 6(2), JCMC621.

Sklodowski, J., \& Jurkowska, A. (2015). Charakterystyka sylwetki i zainteresowań uczestników turystyki birdwatchingowej w Polsce. [Profile and interests of bird-watching tourists in Poland.] Studia i Materiały Centrum Edukacji Przyrodniczo-Leśnej, 17, 203-208.

Snäll, T., Kindvall, O., Nilsson, J., \& Pärt, T. (2011). Evaluating citizen-based presence data for bird monitoring. Biological Conservation, 144, 804-810. 
379 Song, J., \& Stough, C. (2000). The relationship between morningness-eveningness, time-of-day, speed of information processing, and intelligence. Personality and Individual Differences, 29(6), 1179-1190.

Tęgowska, E., Sobocińska, P, \& Maliszewska, J. (2014). Disruption of circadian rhythmicity-An exploratory study in Poland. Personality and Individual Differences, 66, 98-101.

Wałęga, A., Wałęga, G., \& Graczyk, A. (2017). Leisure Time and Income. Some Evidence From Poland. Economic and Environmental Studies, 17, 555-575.

Wang, L., \& Chartrand, T. L. (2015). Morningness-eveningness and risk taking. The Journal of Psychology, 149(4), 394-411.

Wąs, A. (2013). Symbolika i wymiar dydaktyczny zwierząt w literaturze (na przykładzie twórczości Juliusza Słowackiego). [The symbolism and educational dimension of animals in literature (as seen in Juliusz Słowacki's works).] Prace Literackie, 53, 107-115.

Werner, L., Geisler, J., \& Randler, C. (2015). Morningness as a personality predictor of punctuality. Current Psychology, 34(1), 130-139.

Wiersma, Y. (2010). Birding 2.0: Citizen Science and Effective Monitoring in the Web 2.0 World. Avian Conservation and Ecology, 5(2), 1-9. 
402 Yarwood, M. R., Weston, M. A., \& Garnett, S. T. (2014). From little things, big things grow;

403 trends and fads in 110 years of Australian ornithology. Scientometrics, 98(3), 2235-2254.

404

405 Yarwood, M. R., Weston, M. A., \& Symonds, M. R. (2019). Biological determinants of research 406 effort on Australian birds: a comparative analysis. Emu-Austral Ornithology, 119(1), 38-44.

407

408 Żmihorski, M., Dziarska-Pałac, J., Sparks, T. H., \& Tryjanowski, P. (2013). Ecological 409 correlates of the popularity of birds and butterflies in Internet information resources. Oikos, $410 \quad 122(2), 183-190$.

411

412 Żmihorski, M., Sparks, T. H., \& Tryjanowski, P. (2012). The weekend bias in recording rare 413 birds: mechanisms and consequencess. Acta Ornithologica, 47(1), 87-94. 
Figure 1

The mean percentage \pm SE of favourite birds classified as daytime by gender and circadian preference

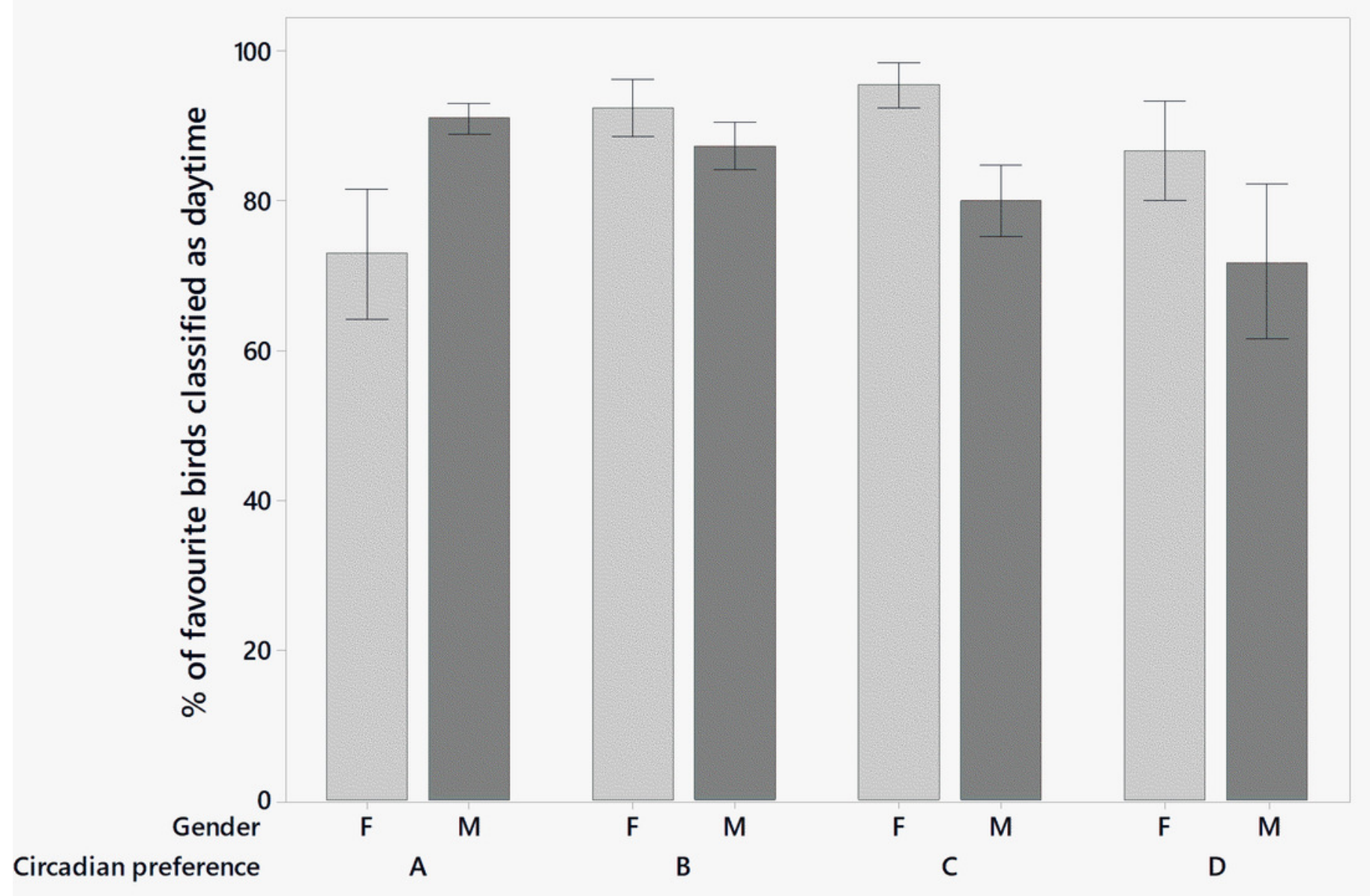




\section{Table $\mathbf{1}$ (on next page)}

The 34 most popular species (those with $\mathrm{n} \geq 5$ ) reported by respondents.

In addition to the overall number and percentages, percentages are also given by professional status (NP nonprofessional, P professional), gender ( $\mathrm{F}$ female, $\mathrm{M}$ male), and circadian preference (categories A-D, see main text). Significance (indicated by *) tested using chi squared or Fisher exact tests for the 12 species with $n \geq 10$. Species in grey shading were categorised as nighttime; all others as daytime. 
1 Table 1. The 34 most popular species (those with $n \geq 5$ ) reported by respondents. In addition to

2 the overall number and percentages, percentages are also given by professional status (NP

3 nonprofessional, $\mathrm{P}$ professional), gender ( $\mathrm{F}$ female, $\mathrm{M}$ male), and circadian preference

4 (categories A-D, see main text). Significance (indicated by *) tested using chi squared or Fisher

5 exact tests for the 12 species with $n \geq 10$. Species in grey shading were categorised as nighttime;

6 all others as daytime.

\begin{tabular}{|c|c|c|c|c|c|c|c|c|c|c|c|}
\hline Species & $\mathbf{n}$ & $\%$ & NP\% & $\mathbf{P \%}$ & & F\% & M\% & $\mathbf{A} \%$ & B\% & $\mathrm{C} \%$ & D\% \\
\hline Grus grus & 28 & 19.6 & 23.3 & 15.9 & & 23.3 & 18.6 & 20.0 & 29.3 & 15.2 & 6.3 \\
\hline Glaucidium passerinum & 16 & 11.2 & 12.3 & 10.1 & & 10.0 & 11.5 & 10.0 & 14.6 & 9.1 & 12.5 \\
\hline Alcedo atthis & 14 & 9.8 & 11.0 & 8.7 & & 10.0 & 9.7 & 12.0 & 7.3 & 9.1 & 12.5 \\
\hline Upupa epops & 14 & 9.8 & 11.0 & 8.7 & & 10.0 & 9.7 & 8.0 & 12.2 & 12.1 & 6.3 \\
\hline Turdus merula & 13 & 9.1 & 11.0 & 7.2 & & 6.7 & 9.7 & 14.0 & 2.4 & 9.1 & 12.5 \\
\hline Aegithalos caudatus & 12 & 8.4 & 8.2 & 8.7 & & 16.7 & 6.2 & 8.0 & 9.8 & 9.1 & 6.3 \\
\hline Ciconia ciconia & 11 & 7.7 & 2.7 & 13.0 & $*$ & 3.3 & 8.8 & 12.0 & 4.9 & 9.1 & 0.0 \\
\hline Vanellus vanellus & 11 & 7.7 & 8.2 & 7.2 & & 6.7 & 8.0 & 2.0 & 9.8 & 9.1 & 18.8 \\
\hline Apus apus & 11 & 7.7 & 12.3 & 2.9 & $*$ & 10.0 & 7.1 & 0.0 & 14.6 & 12.1 & 6.3 \\
\hline Merops apiaster & 11 & 7.7 & 9.6 & 5.8 & & 10.0 & 7.1 & 10.0 & 2.4 & 12.1 & 0.0 \\
\hline Haliaetus albicilla & 10 & 7.0 & 8.2 & 5.8 & & 6.7 & 7.1 & 8.0 & 9.8 & 0.0 & 6.3 \\
\hline Lanius collurio & 10 & 7.0 & 5.5 & 8.7 & & 6.7 & 7.1 & 10.0 & 2.4 & 9.1 & 6.3 \\
\hline Strix aluco & 9 & 6.3 & 9.6 & 2.9 & & 6.7 & 6.2 & 6.0 & 12.2 & 3.0 & 0.0 \\
\hline Circus pygargus & 9 & 6.3 & 8.2 & 4.3 & & 6.7 & 6.2 & 6.0 & 9.8 & 3.0 & 6.3 \\
\hline Corvus monedula & 9 & 6.3 & 2.7 & 10.1 & & 10.0 & 5.3 & 8.0 & 7.3 & 6.1 & 0.0 \\
\hline Ciconia nigra & 8 & 5.6 & 8.2 & 2.9 & & 6.7 & 5.3 & 6.0 & 7.3 & 3.0 & 6.3 \\
\hline Corvus frugilegus & 8 & 5.6 & 4.1 & 7.2 & & 6.7 & 5.3 & 10.0 & 0.0 & 6.1 & 6.3 \\
\hline Corus corax & 8 & 5.6 & 8.2 & 2.9 & & 13.3 & 3.5 & 4.0 & 7.3 & 0.0 & 12.5 \\
\hline Galerida cristata & 8 & 5.6 & 6.8 & 4.3 & & 3.3 & 6.2 & 8.0 & 4.9 & 3.0 & 6.3 \\
\hline Erithacus rubecula & 7 & 4.9 & 6.8 & 2.9 & & 3.3 & 5.3 & 8.0 & 4.9 & 3.0 & 0.0 \\
\hline Bucephala clangula & 7 & 4.9 & 4.1 & 5.8 & & 3.3 & 5.3 & 6.0 & 2.4 & 6.1 & 6.3 \\
\hline Sturnus vulgaris & 6 & 4.2 & 5.5 & 2.9 & & 3.3 & 4.4 & 8.0 & 0.0 & 6.1 & 0.0 \\
\hline Parus major & 6 & 4.2 & 1.4 & 7.2 & & 3.3 & 4.4 & 6.0 & 0.0 & 6.1 & 6.3 \\
\hline Lyrurus tetrix & 6 & 4.2 & 5.5 & 2.9 & & 0.0 & 5.3 & 2.0 & 7.3 & 6.1 & 0.0 \\
\hline Athene noctua & 6 & 4.2 & 4.1 & 4.3 & & 10.0 & 2.7 & 0.0 & 0.0 & 9.1 & 18.8 \\
\hline Aquila chrysaetos & 6 & 4.2 & 8.2 & 0.0 & & 6.7 & 3.5 & 2.0 & 9.8 & 0.0 & 6.3 \\
\hline Limosa limosa & 6 & 4.2 & 5.5 & 2.9 & & 3.3 & 4.4 & 2.0 & 7.3 & 3.0 & 6.3 \\
\hline Tyto alba & 5 & 3.5 & 4.1 & 2.9 & & 0.0 & 4.4 & 6.0 & 0.0 & 6.1 & 0.0 \\
\hline Milvus milvus & 5 & 3.5 & 4.1 & 2.9 & & 3.3 & 3.5 & 6.0 & 0.0 & 3.0 & 6.3 \\
\hline Tetrao urogallus & 5 & 3.5 & 2.7 & 4.3 & & 3.3 & 3.5 & 0.0 & 7.3 & 6.1 & 0.0 \\
\hline Sylvia nisoria & 5 & 3.5 & 2.7 & 4.3 & & 0.0 & 4.4 & 2.0 & 4.9 & 6.1 & 0.0 \\
\hline Coracias garrulus & 5 & 3.5 & 2.7 & 4.3 & & 3.3 & 3.5 & 4.0 & 2.4 & 0.0 & 12.5 \\
\hline Strix nebulosa & 5 & 3.5 & 2.7 & 4.3 & & 6.7 & 2.7 & 4.0 & 0.0 & 3.0 & 12.5 \\
\hline Clanga pomarina & 5 & 3.5 & 6.8 & 0.0 & & 3.3 & 3.5 & 4.0 & 2.4 & 0.0 & 12.5 \\
\hline
\end{tabular}

